\title{
Crude Necator americanus worm extract diminishes pancreatic islet destruction in diabetic non-obese mice (NOD)
}

\author{
Teresiama Velikkakam ${ }^{1}$, Bruna Gazedim ${ }^{1}$, Érica Alessandra Rocha Alves ${ }^{1}$, Ricardo Toshio Fujiwara ${ }^{2}$, \\ Lilian Lacerda Bueno ${ }^{2}$, Jacqueline Araújo Fiuza ${ }^{1}$ and Soraya Gaze,* \\ ${ }^{1}$ Cellular and Molecular Immunology Group, Rene Rachou Institute, Oswaldo Cruz Foundation, \\ Minas Gerais; ${ }^{2}$ Immunology and Genomic of Parasites Laboratory, Department of Parasitology, \\ Federal University of Minas Gerais, Brazil.
}

\begin{abstract}
Diabetes mellitus type 1 is an inflammatory disease caused by an autoimmune response. It is known that its pathogenesis involves a dysfunction in the major histocompatibity complex associated with environment factors, in genetically susceptible people. The destruction of $\beta$ cells is mediated by T and B cells, NK cells and APCs infiltration in the islets of Langerhans, leading to low production of insulin and high glucose blood levels. On the other hand, helminth infections are described as modulators of inflammatory responses due to their capacity to strongly induce Th2 and Treg immune responses. Some studies on autoimmunity diseases, in experimental models and clinical trials, have shown an immune modulation by helminths infections. In this study, we investigated whether Necator americanus crude extract interferes in autoimmune experimental diabetes.
\end{abstract}

KEYWORDS: hygiene hypothesis, Necator americanus, diabetes type 1 .

\section{INTRODUCTION}

Diabetes mellitus type 1 (DM1) is a disease characterized by pancreatic $\beta$ cell selective destruction due to an autoimmune response [1]. Its pathogenesis has many components, and in

\footnotetext{
*Corresponding author: soraya.gaze@fiocruz.br
}

humans involves dysfunction in 40 major histocompatibity complex loci (HLA) [2]. Environment elements, like diet and infections, have an important role in this disease progress since they affect the immune system, especially in genetically susceptible people [3]. In the majority of the cases, DM1 is latent and asymptomatic for several years. Clinical manifestations only appear if $60-90 \%$ of pancreatic $\beta$ cells are destroyed by the immune system and insulin production is not enough to control glucose levels in the blood [4].

It is known that the destruction of $\beta$ cells is mediated by infiltration of $\mathrm{T}$ and $\mathrm{B}$ cells, NK cells and APCs in the islets of Langerhans $[5,6]$. Several studies have demonstrated that, during the progression of the disease, the activation of $\mathrm{T}$ regulatory (Treg) cells culminates with a modulatory response capable of stopping the $\beta$ cell autoantibody production and autoreactive $\mathrm{T}$ cell effectiveness, evolving in a downmodulation in DM1 [3, 7-9].

Helminth infections are described as modulators of inflammatory responses due to their capacity to strongly induce Th2 and Treg immune responses $[10,11]$. Some studies have shown that DM1 in NOD mice may be ameliorated by helminths. This property has been attributed to the fact that epitopes from helminths were able to change the microenvironment of DM1 inflammation inducing Treg cells to produce IL-4, IL-10 and TGF- $\beta$ [12, 13]. Schistosoma mansoni antigens secreted by 
eggs were also able to reduce Treg cell proliferation, preventing DM1 in 4-week old NOD mice [14]. Other autoimmune diseases can also be moderated by helminths infections in experimental models. Studies with autoimmune encephalomyelitis [15], colitis [16], sclerosis [17] and rheumatoid arthritis [18] also showed that helminths and/or their products were able to prevent or suppress autoimmune diseases. However, it is not clear which helminths can ameliorate and how they act in experimental DM1. Thus, this study evaluated the effect of crude antigens from adult Necator americanus in NOD mice model of DM1. The therapeutic properties of this parasite have been widely investigated in other autoimmune diseases, as well as celiac disease in humans.

\section{METHODS}

\section{Mice}

Non-obese diabetic (NOD) female mice aged 4 weeks obtained from Science and Technology in Biomodels Institute (Fiocruz) were tested negative for helminthes and protozoa. They were kept for two weeks in the same environmental conditions used in the experimental protocol for adaptation. Animals were kept in micro-isolator racks during the entire experimental period. All the manipulations were carried out under a sterile environment. Mice were divided into control (treated with Phosphate-buffered saline "PBS") and AdEx (treatment) groups with 15 mice in each study group. All experimental protocols were reviewed and approved by Federal University of Minas Gerais Ethical Committee (license number 389/2012).

\section{Necator americanus crude extract (AdEx)}

Hamsters were infected, via gavage, with 100 $N$. americanus infective larvae stage. At day 42 post infection, animals were euthanized and adult worms were removed from intestine, washed with PBS plus antibiotics and sonicated in PBS. The solution was centrifuged at $500 \mathrm{~g}$ and supernatant was filtered at $0.22 \mu \mathrm{M}$. Protein concentration was measured using microBCA kit according to manufacturer's protocol (Pierce). The antigen was kept at $-80{ }^{\circ} \mathrm{C}$ until used. Antigens from $N$. americanus were kindly donated by Dr. Ricardo Fujiwara (UFMG).

\section{Experimental design}

NOD female mice (6 weeks old) were individually identified and monitored for 18 weeks. During this period, groups received, 3 times a week, $100 \mu \mathrm{L}$ of PBS (control) or $15 \mu \mathrm{g}$ AdEx per dose by intraperitoneal injection. Once a week, tail blood samples were collected to manufacture blood smear slides and to measure glycemia. At the end of 18 weeks treatment, mice were euthanized with overdose of xylazine and ketamine injected in the peritoneal cavity. Blood, pancreas and spleen were collected to measure immunological parameters.

\section{Blood glycemia measurement}

Once a week, tail blood was placed in a tape to measure glycemia (ACCU-Check Active, Roche). All collections were done around the same hour in the day to decrease variation. Blood glycemia was considered non-fasten since the food was available all the time. Values were expressed in $\mathrm{mg} / \mathrm{dL}$ and levels higher than $200 \mathrm{mg} / \mathrm{dL}$ were considered abnormal.

\section{Blood smear slides}

Once a week, a drop of blood was collected from the tail to make blood smear slides. Then, blood cells were stained with hematology staining kit (Laborclin), in accordance with manufacturer's instructions. Cells were analyzed under optical microscopy and the relative number (\%) of circulating eosinophils, lymphocytes, neutrophils, basophils and monocytes was assessed by counting one hundred leukocytes, following Nascimento protocol [19].

\section{Histological analysis}

Pancreas was carefully removed, identified and placed in $4 \%$ formalin buffer for fixation. Briefly, hematoxylin and eosin staining was performed on $4-\mu \mathrm{m}$ sections of formalin-fixed paraffinembedded pancreas and placed on sylanized glass slides [19]. Slides were analyzed using optical microscope and the most preserved cut was selected to count and analyze all the pancreatic islets per animal. Islets were classified according to morphology and inflammatory infiltrate: without insulitis, moderate insulitis, peri-insulitis, and severe insulitis, according to the description given before [20]. 


\section{Flow cytometry}

After euthanasia, spleens were collected and macerated in PBS through a $70 \mu \mathrm{M}$ cell strainer (BD Falcon). Cell suspension was centrifuged at $300 \mathrm{~g}$ and supernatant was discarded. Red blood cells were lysed with sterile distilled water, and leucocytes were centrifuged at $300 \mathrm{~g}$, resuspended and counted in RPMI1640 (Gibco) supplemented with $10 \%$ heat-inactivated fetal bovine serum (Cultilab) with gentamicin $40 \mu \mathrm{g} / \mathrm{mL}$ (SigmaAldrich). Leucocytes at $1 \times 10^{6}$ were then kept in short period culture $(4 \mathrm{~h})$ with Brefeldin A $(10 \mu \mathrm{g})$ (Sigma-Aldrich), $5 \mu \mathrm{g}$ PMA (Sigma-Aldrich) and $50 \mu \mathrm{g}$ Ionomycin (Sigma-Aldrich). Later, cells were centrifuged, Fc receptor was blocked according to manufacturer's protocol (BD Biosciences) and stained with anti-cytokine antibodies according to Fiuza et al., 2015 (Vaccine 2015 (33) 208-288). Antibodies (eBiosciences) used were: CD3 FITC (clone 145-2C11), CD4 PerCP-Cy5.5 (clone RM4-4), CD8 BV421 (clone 53-6.7), CD62L BV605 (clone MEL-14), CD25 BV510 (clone PC61). Cells were then fixed, permeabilized and stained for the cytokines (Phycoerytrin - PE) IL-4 (clone 11B11), IL-12p40 (clone C15.6), IFN- $\gamma$ (clone XMG1.2), TNF- $\alpha$ (clone MP6-XT22), IL-5 (clone TRFK5), IL-17A (clone TC11-18H10.1) and IL-10 (clone JES5-16E3). Data for $1 \times 105$ lymphocytes (gated by forward and side scatter) were acquired with a FACS Fortessa flow cytometer and analyzed using FlowJo software (both from BD Biosciences). Isotype controls were used in all experiments.

\section{Nitric oxide measurement}

Nitric oxide was measured in the splenocyte 4-hculture supernatant and in the serum collected after 18-week treatment. Griess indirect reaction kit was used according to manufacture's protocol (Pierce) [21]. Plates were read in Spectra-Max ${ }^{\circledR}$ Plus384 microplate reader (Molecular Devices) at $540 \mathrm{~nm}$. Sample concentration was interpolated in a standard curve, using the sample diluents, and showed as $\mu \mathrm{g} / \mathrm{mL}$.

\section{Serum cytokine concentration}

Blood was centrifuged at $10,000 \mathrm{~g}$ and sera were obtained and stored at $-80{ }^{\circ} \mathrm{C}$ until individual testing for cytokine levels. Sera were thawed only once and serum levels of IL-17A, TNF- $\alpha$, IL-6, IFN- $\alpha$, IL-2, IL-4 and IL-10 were quantified using the BD Cytometric Bead Array (CBA) Mouse Th1/Th2/Th17 Cytokine kit (BD Biosciences) following the manufacturer's instructions. In addition, serum levels of IL-6, IL-10, MCP-1, IFN- $\gamma$, TNF- $\alpha$ e IL-12p70 were measured using BD Cytometric Bead Array (CBA) Mouse Inflammation kit (BD Bioscienses) according to manufacturer's protocol. Data were acquired with FACS Verse (BD Biosciences) and analyzed using Flowjo 6.0 (BD Biosciences). Lyophilized cytokines were used as standard and values were expressed/showed as $\mathrm{pg} / \mathrm{mL}$. All values below the detection limit were considered zero.

\section{Real-time quantitative polymerase chain reverse (PCR) reaction}

Freshly prepared splenocytes were centrifuged and supernatant was discarded. Trizol (Invitrogen) solution was added and RNA extraction was prepared according to manufacturer's protocol and concentration measured by Nanodrop (Thermo Fisher). After treatment of the RNA with DNAse (RQI Promega), cDNA was synthesized using SuperScript II (Invitrogen). For real-time PCR, 10 ng of cDNA was used per reaction with Syber Green (Promega). All the primers (described in Table 1) were designed and optimized. The experiments were performed using Step One Plus equipment and results analyzed by Step One Software (Applied Biosystems). Results are expressed by $2^{\wedge}$ (CT test- CT control), and betaactin was chosen as the housekeeping gene.

\section{Statistical analysis}

T test with Holm-Sidak post-test was used for multicomparisons. Mann-Whitney test was used when samples were not normally distributed. Spearman correlation was used for comparative analysis between glucose level and cell population frequency. Statistical significance was considered if $\mathrm{p}$ value $\leq 0.05$. All data was analyzed using GraphPad Prism 6.0 software (GraphPad).

\section{RESULTS}

\section{Blood glycemia was not affected by AdEx treatment}

Blood glucose levels were measured weekly, in the morning, for 18 weeks. During the whole 
Table 1. Primers designed for each tested gene used in real-time PCR.

\begin{tabular}{|c|c|c|c|}
\hline Gene & Forward & Reverse & Amplicon \\
\hline$\beta$ - $a c t$ & TTGTTACCAACTGGGACGAC & ACGGTTGGCCTTAGGGTT & 125 \\
\hline$i f n-\gamma$ & CGGCTGACCTAGAGAAGACA & GTAACAGCCAGAAACAGCCA & 160 \\
\hline$t g f-\beta$ & TTTAGGAAGGACCTGGGTTG & CTTGCGACCCACGTAGTAGA & 216 \\
\hline$i l-12 a$ & CTTTGATGATGACCCTGTGC & GCAGAGTCTCGCCATTATGA & 183 \\
\hline$i l-5$ & GCTGGCCTCAAACTGGTAAT & TGGTAACATGCACAAAGCCT & 152 \\
\hline$i l-21$ & AAATGCCCTTCCTGTGATTC & CTGCATTCGTGAGCGTCTAT & 191 \\
\hline arginase & GGTTCTGGGAGGCCTATCTT & AAGCAAGCCAAGGTTAAAGC & 171 \\
\hline retlna & GTCCTGGAACCTTTCCTGAG & AGCTGGATTGGCAAGAAGTT & 180 \\
\hline$i l-10$ & TAAGGGTTACTTGGGTTGCC & TCACTCTTCACCTGCTCCAC & 213 \\
\hline
\end{tabular}

experimental period, there was no difference in the circulating levels of glucose between AdExtreated and placebo groups (Figure 1A). During the 18-week treatment, four animals per control group and three mice per AdEx group showed levels above $600 \mathrm{mg} / \mathrm{dL}$ and all died before the next measurement. Since all NOD mice were individually identified, glucose levels were also analyzed considering the first measurement (week 1). Results were plotted in heatmap (Figure 1B), where gray indicates lower variation and red higher variation compared to the first week of treatment. As demonstrated in Figure 1B, AdExtreated group showed a tendency to have lower variation in the blood glucose levels than PBS group (Figure 1B).

\section{NOD mice presented decreased severity of insulitis after AdEx treatment}

Pancreas from each mouse was evaluated by optical microscopy after H\&E staining. The severity of insulitis was analyzed by the total number of Langerhans islets and size of inflammation around them. When data was analyzed, AdEx group showed higher number of Langerhans islets than PBS group (Figure 2A). Moreover, Langerhans islets were larger than those found in the control group. The results also demonstrated that mice treated with AdEx showed $42.3 \%$ of islets without insulitis, $11.5 \%$ with peri insulitis, $15.4 \%$ with moderate insulitis and $30.8 \%$ with severe insulitis. On the other hand, animals treated with PBS showed $29.7 \%$ of islets without insulitis, $18.5 \%$ with peri insulitis, $11.1 \%$ with moderate insulitis, and $40.7 \%$ with severe insulitis (Figure 2B), indicating a decrease of the inflammatory response in the AdEX-treated group.

\section{AdEx treatment induces an increase in circulating eosinophils}

AdEx injections increased the relative number of circulating eosinophils. This increase was significant as early as second week of treatment and remained elevated throughout the whole treatment compared to the PBS control group (Figure 3). The relative number of lymphocytes was also increased in the AdEx group (data not shown). The other cell subtypes analyzed, including neutrophils, mastocytes, basophils and monocytes, showed no difference between both analyzed groups.

\section{A mixed immune response profile was observed after AdEx treatment}

The profile of cytokines induced by AdEx treatment was evaluated in two compartments: Sera and splenocytes. In the sera from NOD mice, the AdEx treatment induced an increase in IL-2 $(\mathrm{p}=0.0138$; Figure 4A), IFN- $\gamma(\mathrm{p}=0.0072$; Figure 4B), IL-12 ( $=0.0138$; Figure $4 \mathrm{C})$ and IL-6 ( $\mathrm{p}=0.0099$; Figure 4D), all considered inflammatory cytokines, compared to the control group. In addition, AdEx-treated mice presented 


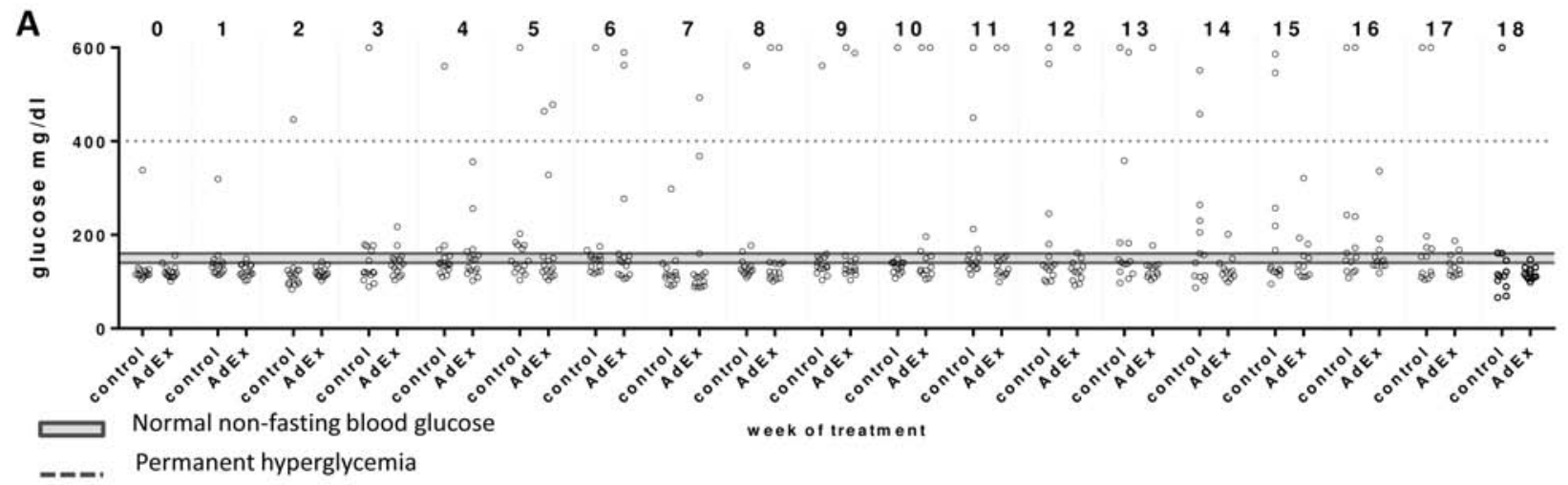

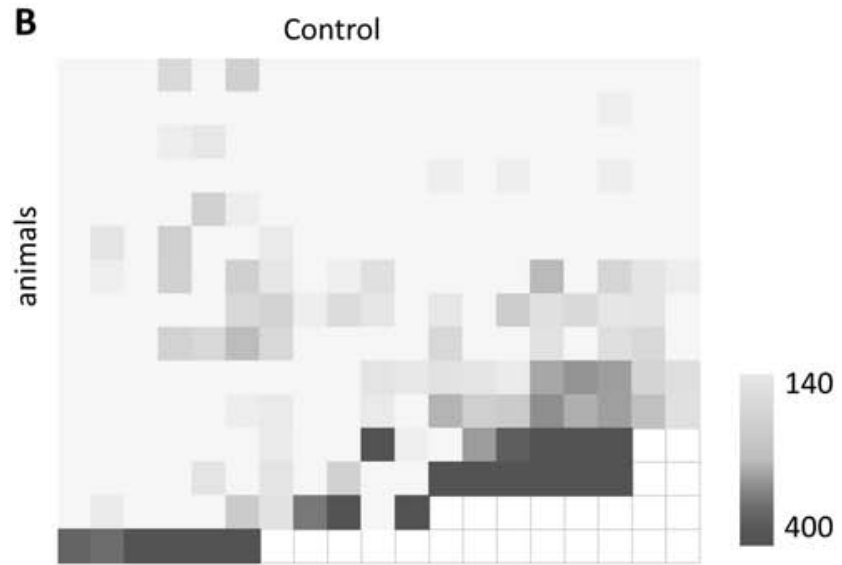

Weeks of treatment

$0-18$

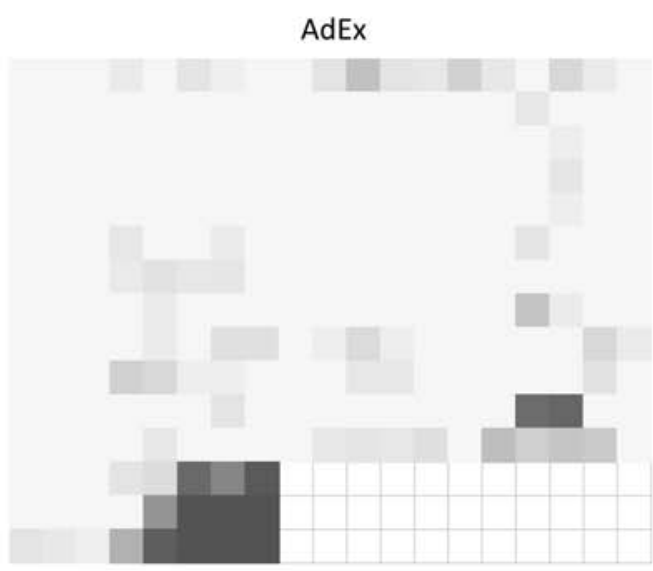

Weeks of treatment

0-18

Figure 1. Blood glucose level distribution after 18 weeks of AdEx treatment. (A) Blood glucose levels (mg/dL) in mice from treated (AdEx) and control (PBS) groups from week 0 to 18. Dashed line indicates level of permanent glycemia and gray area normal non-fasting glycemia levels according to [53] (B) Heat map of glycemia levels per week per group. Lower level considered $140 \mathrm{mg} / \mathrm{dL}$ (soft gray) and upper level $400 \mathrm{mg} / \mathrm{dL}$ (dark gray). Empty spots indicate loss of measurement since mice did not survive.

A

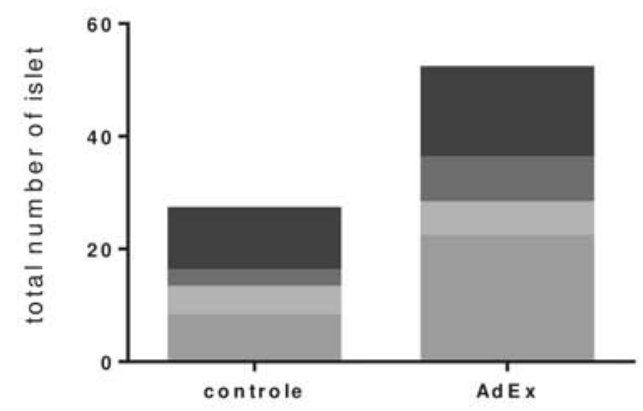

B

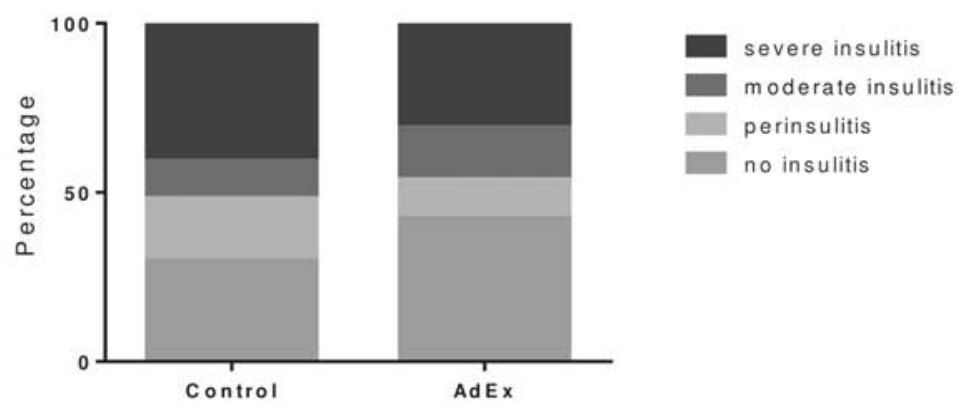

Figure 2. Evaluation of inflammatory infiltrate in Langerhans islets in NOD mice treated with AdEx. Total number (A) and percentage (B) of Langerhans islets presenting or not presenting inflammatory infiltrate. From bottom to top: no insulitis, soft gray - peri insulitis, moderate insulitis, dark gray - severe insulitis. 


\section{Eosinophil}

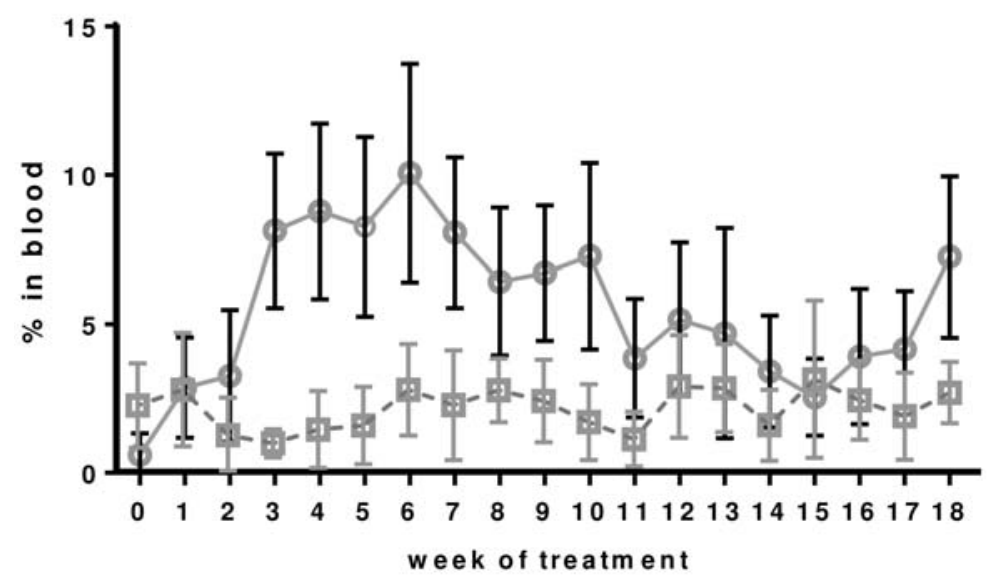

Figure 3. Percentage of eosinophils in the blood circulation. Square - control group, circle - AdEx group. Data presented as mean \pm SEM.

\section{A}

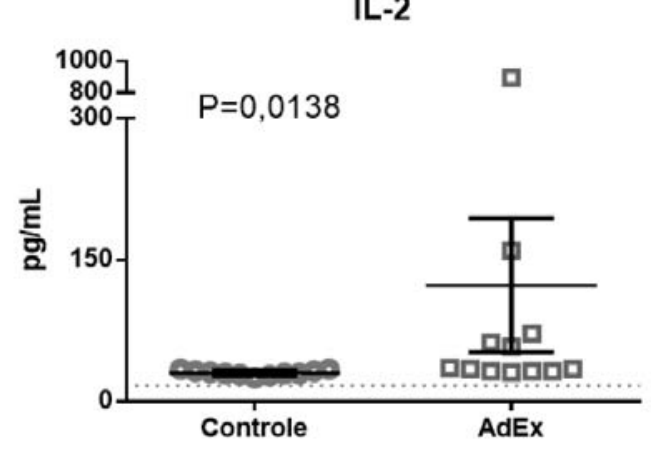

\section{C}

IL-12

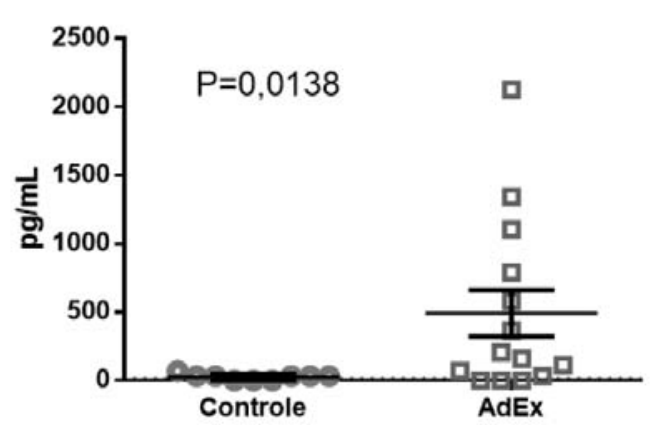

B

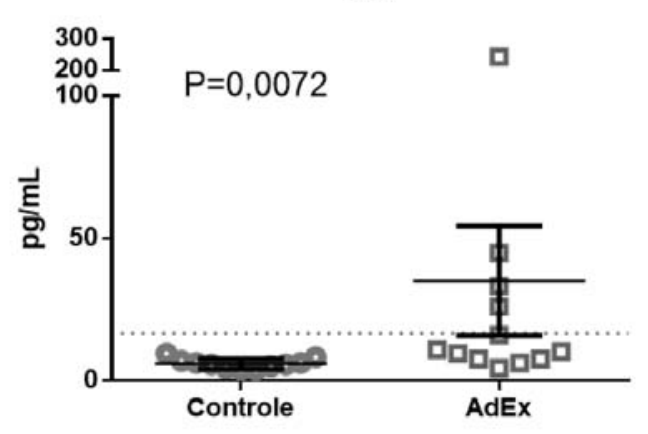

D

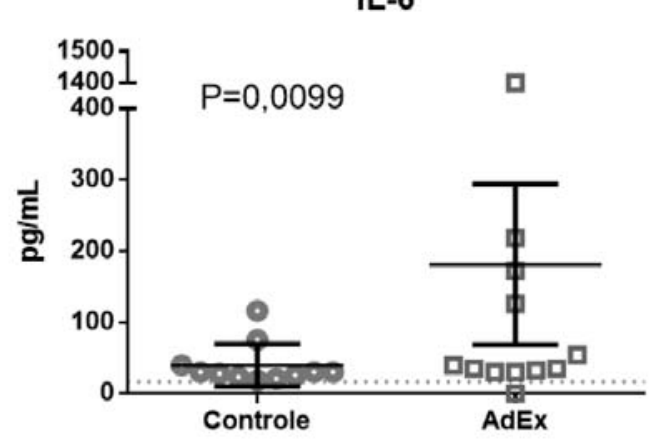

Figure 4 
Figure 4 continued..

E

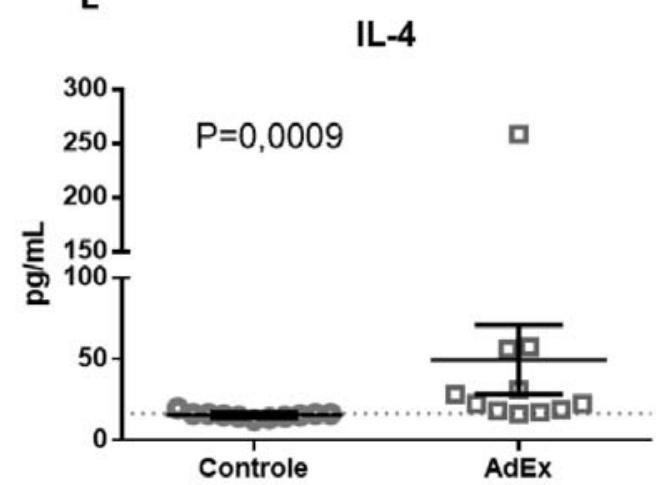

$\mathbf{F}$

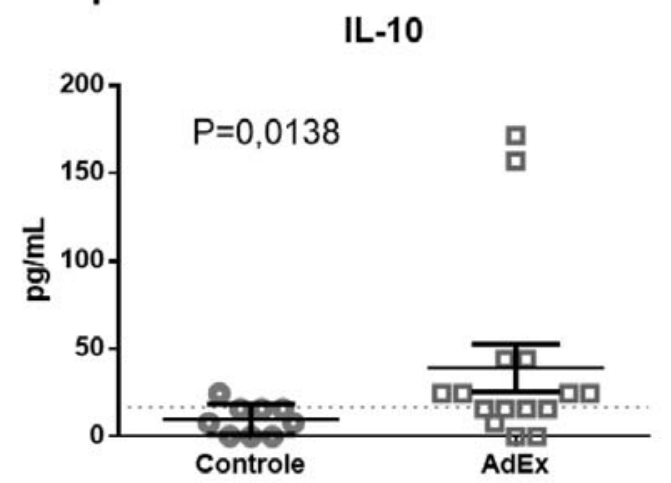

Figure 4. Serum levels of cytokines in NOD mice treated or not treated with AdEx. (A) IL-2; (B) IFN- $\gamma$; (C) IL-12; (D) IL-6; (E) IL-4; (F) IL-10. Circles - control (PBS) group. Square - treated (AdEx) group. Statistical analysis was performed using unpaired $\mathrm{T}$ test. Data presented as mean \pm SEM. Dashed line indicates detectable levels according to manufacturer's protocol.

increased serum levels of IL-4 ( $=0.0009$; Figure $4 \mathrm{E})$ and IL-10 ( $=0.0138$; Figure $4 \mathrm{~F})$ compared to the PBS-treated animals, showing that the AdEx treatment induced a mixed profile of circulating cytokines. Since we observed increased production of modulatory cytokines in sera from AdEx-treated mice, we also analyzed short cultured splenocytes, in order to understand which cells were producing those cytokines. Interesting, our results demonstrated that, after 18-week treatment, the AdEx group has increased IL-4 production by $\mathrm{CD}^{+}(\mathrm{p}=0.0086$; Figure $5 \mathrm{~A})$ and $\mathrm{CD}^{+}(\mathrm{p}=0.0129$; Figure 5B) $\mathrm{T}$ cells. In addition, AdEx mice presented higher IL-10 production, not only by $\mathrm{CD}^{+}(\mathrm{p}=0.0086$; Figure $5 \mathrm{C})$ and $\mathrm{CD}^{+}(\mathrm{p}=0.0086$; Figure 5D) T cells, but also by macrophages $(p=0.0086$; Figure $5 F)$, compared to the PBS group. Furthermore, in the splenocyte culture from AdEx group, the production of IL-10 by the subpopulation of $\mathrm{CD} 4^{+} \mathrm{T}$ cells expressing $\mathrm{CD} 25$ was also higher $\left(\mathrm{CD}^{+} \mathrm{CD} 25^{+}\right)$than in the culture from PBS control group ( $p=0.031$, Figure $5 \mathrm{E})$. Taken together, results from splenocyte culture showed that treatment with ADEX increased the production of modulatory cytokines by splenic leukocytes. Other cytokines evaluated by this study did not show statistical differences between analyzed groups.

Levels of mRNA, related with inflammatory and modulatory immunological profiles, were evaluated (IFN- $\gamma$, IL-12a, IL-5, IL-21, Retnla, Arginase, TGF- $\beta$ and IL-10) by qPCR. RETNLA (Fizz1) showed higher expression in AdEx group $(\mathrm{p}=0.0116)$ compared to control (Figure 6A). However, the expression of other regulatory genes, such as Arginase, TGF- $\beta$ and IL-10, was lower in AdEx mice compared to control group $(\mathrm{p}=0.0117, \mathrm{p}=0.0369$ and $\mathrm{p}=0.0113$, respectively) (Figure 6B, C and D, respectively). No statistical differences were observed when analyzing the expression of IFN- $\gamma$, IL-12a, IL-5, IL-21 (data not shown).

\section{AdEx treatment induces decrease of nitric oxide}

The levels of NO in sera and culture supernatant from splenocytes were analyzed by Griess reaction. In both, the treatment with AdEx for 18 weeks induced lower levels of nitric oxide when compared to control PBS group (sera, $\mathrm{p}=0.002$ and supernatant, $\mathrm{p}=0.003$ ) (Figures $7 \mathrm{~A}$ and $\mathrm{B}$ ), showing that AdEx injection influences free radical production in NOD mice.

\section{Higher levels of glucose are negatively correlated to levels of modulatory cytokines}

Correlations were made between levels of glucose and production of IL- 4 and IL- 10 by CD4 ${ }^{+}$and $\mathrm{CD}^{+} \mathrm{T}$ cells. After 18 weeks of treatment with AdEx, mice that presented higher levels of glucose showed a decrease of IL4CD4 $(p=0.0183$, $r=0.6714$; Figure 8A), IL4CD8 $(p=0.0174$, 

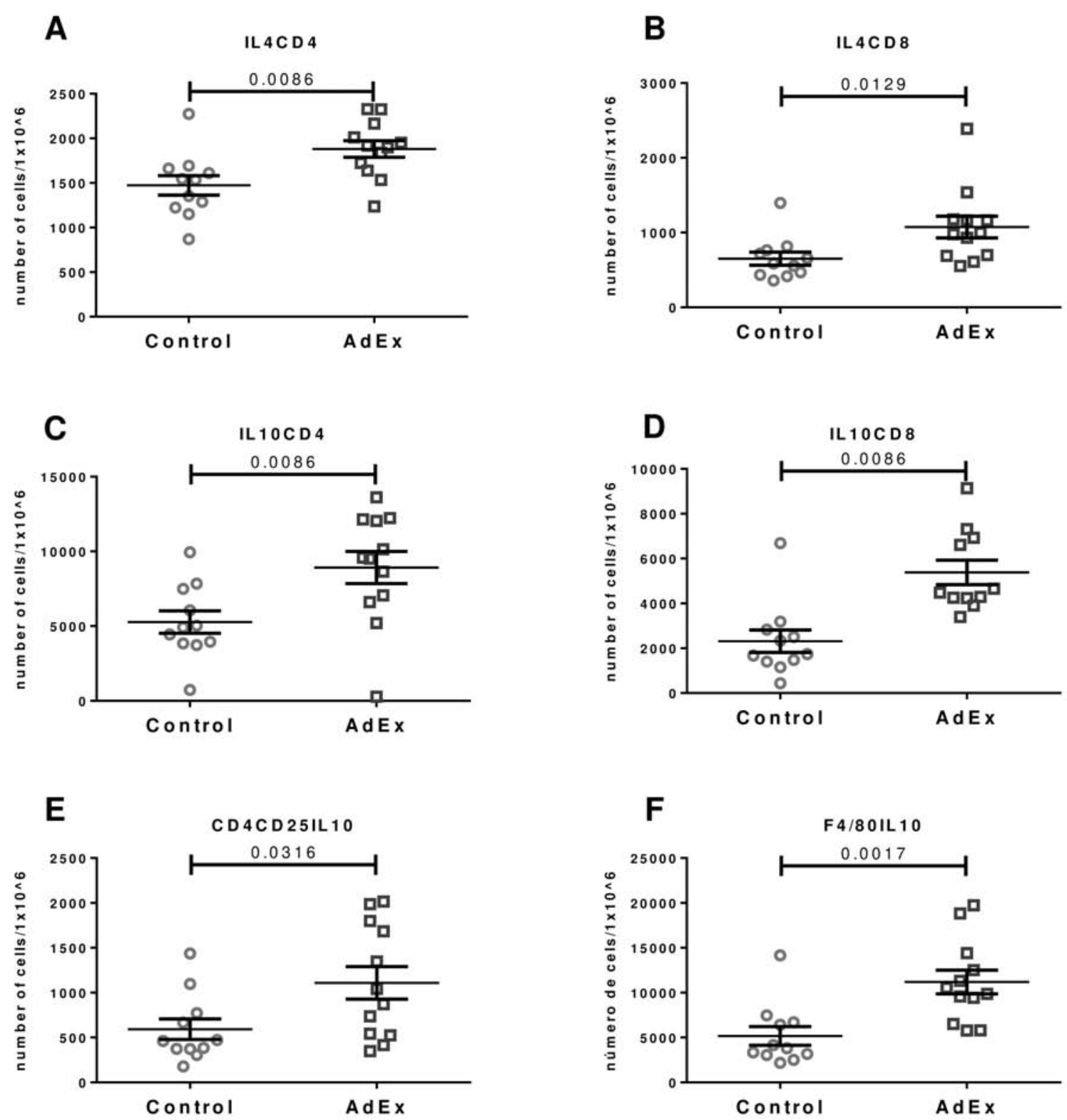

Figure 5. Evaluation of the cytokine levels in the culture supernatant of splenocytes from NOD mice treated or not treated with AdEx. (A) IL4CD4; (B) IL-4CD8; (C) IL10CD4; (D) IL10CD8; (E) CD4CD25IL-10; (F) F4/80IL-10. Circles - control (PBS) group. Square - treated (AdEx) group. Statistical analysis was performed using unpaired $\mathrm{T}$ test. Data presented as mean \pm SEM.

$\mathrm{r}=0.6749$; Figure 8B) and IL10CD4 ( $\mathrm{p}=$ $0.00264, r=0.6797$; Figure $8 C$ ), being correlated negatively.

\section{DISCUSSION}

The use of helminthic parasites as therapeutic tools for chronic diseases has been studied by many groups [10, 22-34]. Particularly for DM1, the use of pathogens or pathogen-derived products has shown to modulate autoimmune diabetes in the NOD mice [30-37]. The present work also demonstrated important implications in NOD mice, such as a mixed Th1/Th2 response and the decrease of damage in the pancreas. It is important to note that in our study, mice showed lower incidence of diabetes than previously 
A

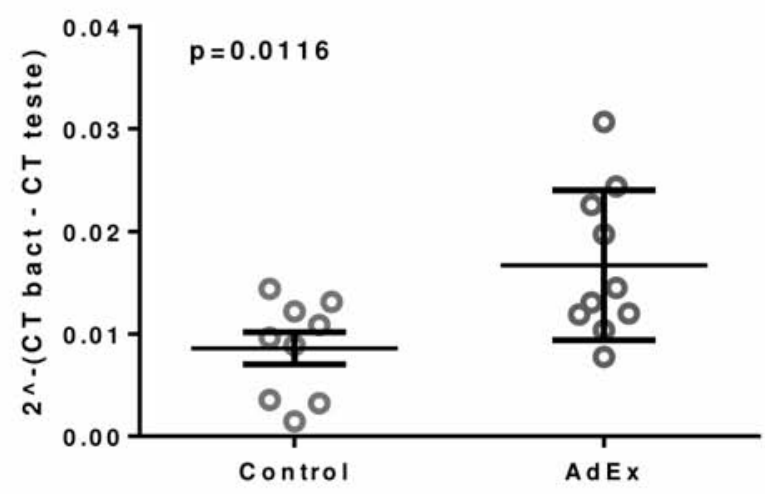

C

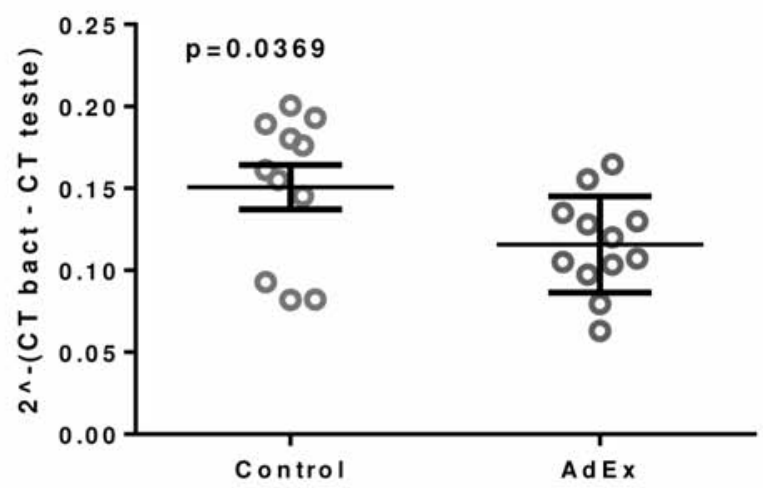

B

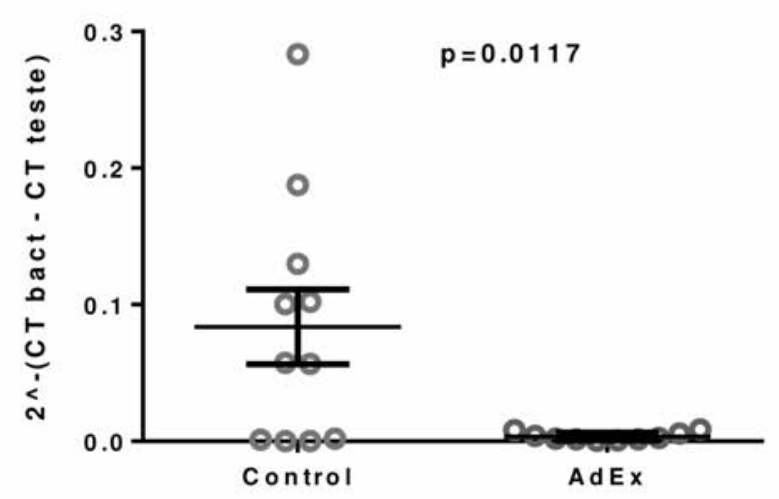

D

IL -10

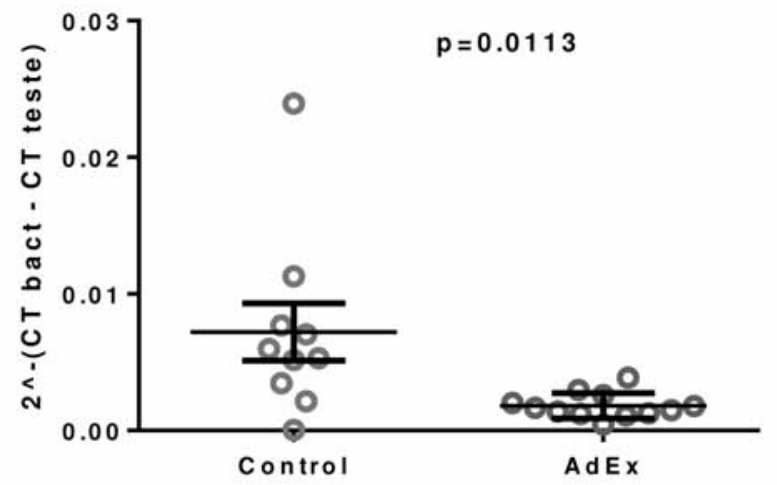

Figure 6. Fresh spleen cell mRNA expression evaluation. (A) RETNLA (FIZZ-1); (B) Arginase; (C) TGF; (D) IL10. Circles - control (PBS) group. Square - treated (AdEx) group. Statistical analysis was performed using unpaired $\mathrm{T}$ test. Data presented as mean $\pm \mathrm{SEM}$.
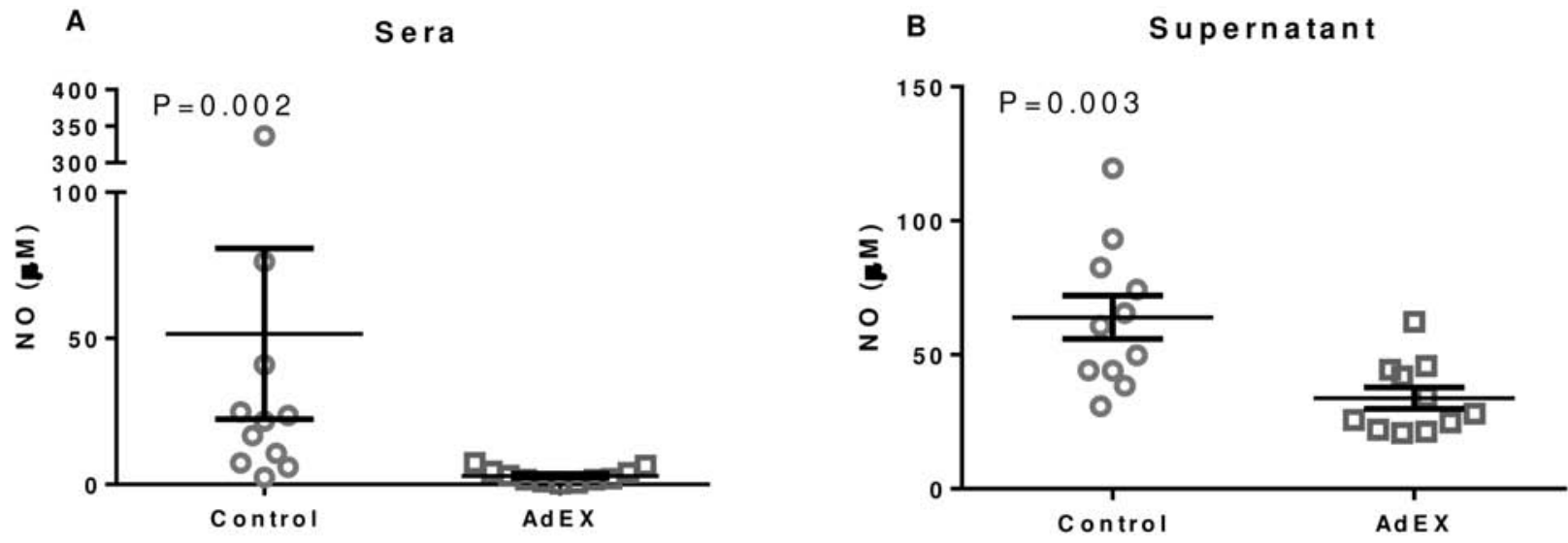

Figure 7. Nitric oxide production evaluation. (A) Sera; (B) Supernatant of $4 \mathrm{~h}$ spleen cell culture. Circles - control (PBS) group. Square - treated (AdEx) group. Statistical analysis was performed using unpaired $\mathrm{T}$ test. Data presented as mean \pm SEM. 

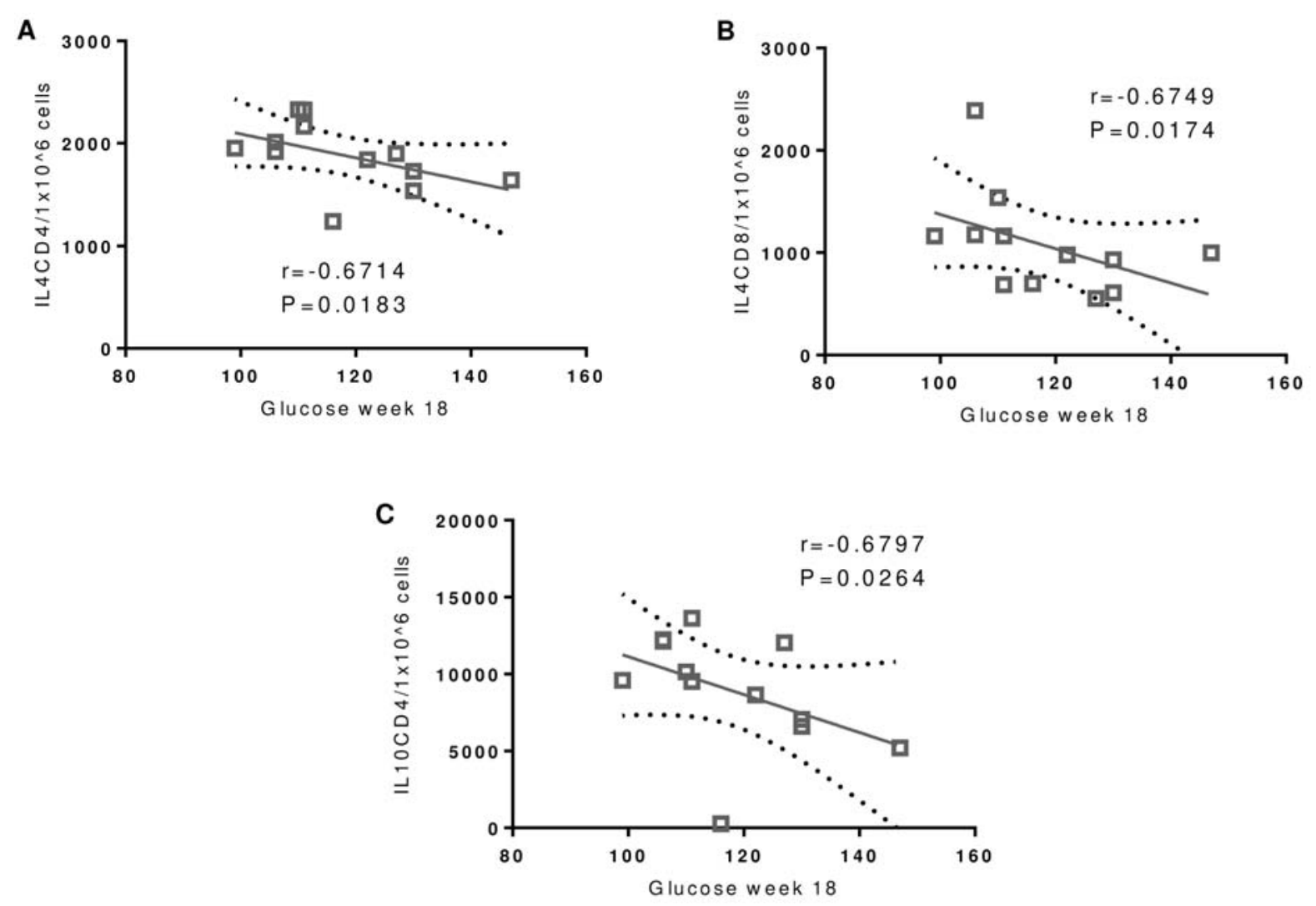

Figure 8. Correlation between $4 \mathrm{~h}$ culture of spleen cell population and glucose level at week 18. (A) IL4CD4; (B) IL-4CD8; (C) IL10CD4 versus glucose level at week 18 in treated (AdEx) group (square). Line correlation Dashed line: $95 \%$ of distribution.

reported (Liu et al., 2009 [30]). It is known that age is one of the important factors that influence the normal glucose levels. In NOD mice, there are evidences that diabetes may develop as late as 30 weeks of life [38]. Unfortunately, at the end of the experimental period (18 weeks of treatment), NOD mice were only 24-week old.

When mice were individually compared, AdEx treatment was found to show a tendency of keeping glucose levels near the week 0 levels. Interestingly, the glucose blood levels corroborate the inflammation found in the pancreas. Histology analyses showed that the pancreatic islet number of the two analyzed groups did not have any statistical differences. This could be reason why diabetes had lower rates in this study. However, the AdEx treatment seems to influence the inflammatory infiltrate in the pancreas since $42 \%$ of the islets had no insulitis in the treatment group compared to $29.7 \%$ in the control group.
It has been shown that $N$. americanus infection can induce a strong Th2 response, but Th1 component is also present [39]. AdEx used in this study is composed of proteins from whole adult worms, males and females, and could explain the mixed response observed. Eosinophils have been shown to play an important effector role in helminth infections. They could polarize the response [40], inducing preferably Th2 response through the release of mediators like indoleamine 2,3-dioxygenase and eosinophil-derived neurotoxin [41]. Since there was an increase of eosinophils at early weeks of injection, they could contribute in favoring a strong Th2 immune response, as observed, in the presence of $N$. americanus antigens and could be one of the mechanisms to decrease damage in the pancreas.

Splenocytes were also affected by AdEx treatment demonstrating its capacity to influence several immune sites. After 18-week treatment, $\mathrm{CD}_{4}{ }^{+}$and 
$\mathrm{CD}^{+} \mathrm{T}$ cells producing IL-4 and IL-10 showed an increased number in the spleen compared to control placebo group. Other studies had shown that helminths can stimulate Treg and other types of cells inducing IL-10 and IL-4 production, and this could ameliorate inflammation caused by Th1 and Th17 [40, 42, 43]. This is particularly important since NOD mice have shown lymphopenia, especially for $\mathrm{CD}^{+}$and Treg cells [44, 45]. A lower IL-4 intrinsic production by NOD mice has also been described [46, 47]. Thus, AdEx treatment increased the IL-4 and IL-10 systematically to help control the inflammation in the pancreas.

Moreover, IL-12, IL-2 and IL-6 levels were increased in treated mice sera. Nevertheless, how (the production of these cytokines in different tissue compartments interferes in DM1 pathology still needs a deeper understanding. The corroboration that the steady state of AdEx treatment, even if it is only for 18 weeks, is an attempt of controlling inflammation, also demonstrated by lower levels of nitric oxide production in treated group compared to control group. This could be a result of a possible alternative macrophage induction by AdEx producing IL-10. Alternative activated macrophages express Arginase- 1 inducing Lornitin production and are involved in wound healing [48]. On the other hand, classic macrophages convert arginin in nitric oxide causing lesion by respiratory burst and $\beta$ cells killing [48]. This could be one of the factors involved in the pancreatic islet preservation observed in AdEx group. The induced mixed immune profile was also demonstrated by mRNA levels. Although Arginase mRNA was decreased in AdEx-treated group, FIZZ1 (Retnla) was increased compared to control group. FIZZ1 is a molecule expressed by alternative macrophages and is also involved in wound healing [49]. Other studies also demonstrate that helminthes induce higher levels of FIZZ1 in mice $[50,51]$.

An association between AdEx treatment and diabetes amelioration was demonstrated by correlations between blood glucose levels and IL-4 and IL-10 production by $\mathrm{CD}^{+}$and $\mathrm{CD} 8^{+}$ $T$ cells. Negative correlations suggest a potential effect of AdEx to reduce the damage caused by diabetes type 1 in mice. Thus, this study corroborates the hypothesis that helminthes antigens can potentially modulate and modify the immune response to benefit mice affected by DM1. Other studies on infections or antigen administration using Schistosoma mansoni, Taenia crassiceps, Heligmosomoides polygyrus, Trichinella spiralis ou Strongyloides venezuelensis showed that helminthes parasites prevented or inhibited DM1 in NOD mice [52]. However, this positive effect only happened if antigen administration or infection started before insulitis establishment, usually around 4 weeks of age in NOD mice [13].

\section{CONCLUSION}

In conclusion, this study showed the potential therapeutic use of Necator americanus antigens in preventing DM1 progression by decreasing $\beta$ cell destruction. This study supports the need for further analysis aiming at elucidating the helminth-induced mechanisms in DM1.

\section{ACKNOWLEDGEMENT}

This project received financial support from Conselho Nacional de Pesquisas (CNPq) Universal grant number 444060/2014-6 and Rene Rachou Institute-Fiocruz MG. TV, BGA had scholarship, and JAF had fellowship, from CNPq. RTF and LLB have career fellowship from CNPq. Data and results provided by this manuscript are not plagiarism and were not published anywhere before here. The authors also thank the flow cytometry platform of the Fiocruz Program for the Technological Development Tools for Health (PDTIS). We are very thankful for the help of Dr. Marcelo Antônio Pascoal Xavier.

Sponsorship: CNPq and Fiocruz.

\section{AUTHOR'S CONTRIBUTION}

TV, BGA, EARA, JAF and SG participated in all experiments and analysis. TV, EARA, RTJ, LLB, JAF and SG wrote the manuscript. JAF, EARA and SG designed experiments. RTJ and LLB provided crude $N$. americanus extract.

\section{CONFLICT OF INTEREST STATEMENT}

The authors have no conflicts of interest to declare. All co-authors have seen and agree with the contents of the manuscript. 


\section{REFERENCES}

1. Kahaly, G. J. and Hansen, M. P. 2016, Autoimmun. Rev., 15, 644.

2. Atkinson, M. A. 2014, Diabetes, 63, 3572.

3. Clark, M., Kroger, C. J. and Tisch, R. M. 2017, Front. Immunol., 8, 1898.

4. Coppieters, K. T. and von Herrath, M. G. 2009, Rev. Diabet. Stud., 6, 85.

5. Richardson, S. J., Morgan, N. G. and Foulis, A. K. 2014, Endocr. Pathol., 25, 80.

6. Zóka, A., Somogyi, A. and Firneisz, G. 2012, Orv. Hetil., 153, 1047.

7. Atkinson, M. A., Eisenbarth, G. S. and Michels, A. W. 2014, Lancet, 383, 69.

8. Ferretti, C. and La Cava, A. 2016, Autoimmun. Rev., 15, 236.

9. Askenasy, N. 2016, Immunology, 147, 377.

10. Cançado, G. G., Fiuza, J. A., de Paiva, N. C., Lemos, L. C., Ricci, N. D., GazzinelliGuimarães, P. H., Martins, V. G., Bartholomeu, D. C., Negrão-Corrêa, D. A., Carneiro, C. M. and Fujiwara, R. T. 2011, Inflamm. Bowel Dis., 17, 2275.

11. Motran, C. C., Silvane, L., Chiapello, L. S., Theumer, M. G., Ambrosio, L. F., Volpini, X., Celias, D. P. and Cervi, L. 2018, Front. Immunol., 9, 664.

12. Egro, F. M. 2013, J. Mol. Endocrinol., 51, R1.

13. Berbudi, A., Ajendra, J., Wardani, A. P., Hoerauf, A. and Hübner, M. P. 2016, Diabetes Metab. Res. Rev., 32, 238.

14. Zaccone, P., Burton, O., Miller, N., Jones, F. M., Dunne, D. W. and Cooke, A. 2009, Eur. J. Immunol., 39,1098.

15. Gruden-Movsesijan, A., Ilic, N., MostaricaStojkovic, M., Stosic-Grujicic, S., Milic, M. and Sofronic-Milosavljevic, L. 2010, Parasite Immunol., 32, 450.

16. Smith, P., Mangan, N. E., Walsh, C. M., Fallon, R. E., McKenzie, A. N., van Rooijen, N. and Fallon, P. G. 2007, J. Immunol., 178, 4557.

17. Fleming, J. O. 2013, Int. J. Parasitol., 43, 259.

18. Osada, Y., Shimizu, S., Kumagai, T., Yamada, S. and Kanazawa, T. 2009, Int. J. Parasitol., 39, 457.
19. Alvarenga, D. L. R., Silva, A. H. D. S., Fiuza, J. A., Gaze, S. T., de Oliveira, J. G., Oliveira, R. C., Calzavara-Silva, C. E., Pascoal-Xavier, M. A. and Alves, E. 2018, Int. Immunopharmacol., 60, 179.

20. Ukah, T. K., Cattin-Roy, A. N., Chen, W., Miller, M. M., Barik, S. and Zaghouani, H. 2017, J. Immunol., 199, 894.

21. Granger, D. L., Taintor, R. R., Boockvar, K. S. and Hibbs, J. B. 1996, Methods Enzymol., 268, 142.

22. Elliott, D. E., Urban, J. F. J. R., Argo, C. K. and Weinstock, J. V. 2000, FASEB J 2000, 14, 1848.

23. Elliott, D. E., Li, J., Blum, A., Metwali, A., Qadir, K., Urban, J. F., Weinstock, J. V. 2003, Am. J. Physiol. Gastrointest. Liver Physiol., 284, G385.

24. Elliott, D. E., Setiawan, T., Metwali, A., Blum, A., Urban, J. F. and Weinstock, J. V. 2004, Eur. J. Immunol., 34, 2690.

25. Reardon, C., Sanchez, A., Hogaboam, C. M. and McKay, D. M. 2001, Infect. Immun., 69, 4417.

26. Khan, W. I., Blennerhasset, P. A., Varghese, A. K., Chowdhury, S. K., Omsted, P., Deng, Y. and Collins, S. M. 2002, Infect. Immun., 70, 5931.

27. Summers, R. W., Elliott, D. E., Urban, J. F., Thompson, R. and Weinstock, J. V. 2005, Gut, 54, 87.

28. Summers, R. W., Elliott, D. E., Urban, J. F., Thompson, R. A. and Weinstock, J. V. 2005, Gastroenterology, 128, 825.

29. Croese, J., O'neil, J., Masson, J., Cooke, S., Melrose, W., Pritchard, D. and Speare, R. 2006, Gut, 55, 136.

30. Liu, Q., Sundar, K., Mishra, P. K., Mousavi, G., Liu, Z., Gaydo, A., Alem, F., Lagunoff, D., Bleich, D. and Gause, W. C. 2009, Infect. Immun., 77, 5347.

31. Saunders, K. A., Raine, T., Cooke, A. and Lawrence, C. E. 2007, Infect. Immun., 75, 397.

32. Sutton, T. L., Zhao, A., Madden, K. B., Elfrey, J. E., Tuft, B. A., Sullivan, C. A., Urban, J. F. and Shea-Donohue, T. 2008, Infect. Immun., 76, 4772. 
33. Hübner, M. P., Shi, Y., Torrero, M. N., Mueller, E., Larson, D., Soloviova, K., Gondorf, F., Hoerauf, A., Killoran, K. E., Stocker, J. T. Davies, S. J., Tarbell, K. V. and Mitre, E. 2012, J. Immunol., 188, 559.

34. Imai, S., Tezuka, H. and Fujita, K. 2001, Biochem. Biophys. Res. Commun., 286, 1051.

35. Hübner, M. P., Stocker, J. T. and Mitre, E. 2009, Immunology, 127, 512.

36. Zaccone, P., Fehérvári, Z., Jones, F. M., Sidobre, S., Kronenberg, M., Dunne, D. W. and Cooke, A. 2003, Eur. J. Immunol., 33, 1439.

37. Harn, D. A., McDonald, J., Atochina, O. and Da'dara, A. A. 2009, Immunol. Rev., 230, 247.

38. Kaminitz, A., Mizrahi, K. and Askenasy, N. 2014, Autoimmunity, 47, 105.

39. Geiger, S. M., Caldas, I. R., Mc Glone, B. E., Campi-Azevedo, A. C., De Oliveira, L. M., Brooker, S., Diemert, D., CorrêaOliveira, R. and Bethony, J. M. 2007, Parasite Immunol., 29, 347.

40. Webb, L. M. and Tait Wojno, E. D. 2017, Parasitology, 144, 1288.

41. Spencer, L. A. and Weller, P. F. 2010, Immunol. Cell Biol., 88, 250.

42. Gaze, S., Driguez, P., Pearson, M. S., Mendes, T., Doolan, D. L., Trieu, A., McManus, D. P., Gobert, G. N., Periago, M. V., Correa Oliveira, R., Cardoso, F. C., Oliveira, G., Nakajima, R., Jasinskas, A., Hung, C., Liang, L., Pablo, J., Bethony, J. M.,
Felgner, P. L. and Loukas, A. 2014, PLoS Pathog, 10, e1004033.

43. McSorley, H. J., Hewitson, J. P. and Maizels, R. M. 2013, Int. J. Parasitol., 43, 301.

44. King, C., Ilic, A., Koelsch, K. and Sarvetnick, N. 2004, Cell, 117, 265.

45. Dejaco, C., Duftner, C., GrubeckLoebenstein, B. and Schirmer, M. 2006, Immunology, 117, 289.

46. Delovitch, T. L. and Singh, B. 1997, Immunity, 7, 727.

47. Aoki, C. A., Borchers, A. T., Ridgway, W. M., Keen, C. L., Ansari, A. A. and Gershwin, M. E. 2005, Autoimmun. Rev., 4, 373.

48. Reyes, J. L. and Terrazas, L. I. 2007, Parasite Immunol., 29, 609.

49. Anthony, R. M., Rutitzky, L. I., Urban, J. F., Stadecker, M. J. and Gause, W. C. 2007, Nat. Rev. Immunol., 7, 975.

50. Anthony, R. M., Urban, J. F., Alem, F., Hamed, H. A., Rozo, C. T., Boucher, J. L., Van Rooijen, N. and Gause, W. C. 2006, Nat. Med., 12, 955.

51. Nair, M. G., Gallagher, I. J., Taylor, M. D., Loke, P., Coulson, P. S., Wilson, R. A., Maizels, R. M. and Allen, J. E. 2005, Infect. Immun., 73, 385.

52. Ajendra, J., Berbudi, A., Hoerauf, A. and Hübner, M. P. 2016, Clin. Immunol., 164, 119.

53. Leiter, E. H., Prochazka, M. and Coleman, D. L.1987, Am. J. Pathol., 128, 380. 